\title{
SISTEM PENGAMBILAN KEPUTUSAN PEMETAAN PELATIHAN TEKNOLOGI INFORMASI UNTUK PENYANDANG DISABILITAS TUNA RUNGU HARD OF HEARING MENGGUNAKAN METODE ANALYTICAL HIERARCHY PROCESS
}

(AHP)

\author{
Siti Ummi Masruroh, Ahmad Arya Swaraja, Imam M. Shofi \\ Teknik Informatika, Fakultas Sains dan Teknologi \\ Universitas Islam Negeri Syarif Hidayatullah Jakarta \\ ummi.masruroh@uinjkt.ac.id, arya@mhs.uinjkt.ac.id, imam@uinjkt.ac.id
}

\begin{abstract}
Law Number 8 of 2016 states that this is part of the Republic of Indonesia which has the same rights and obligations. Therefore, it is necessary to improve the social balance of disability. One way to improve it is by providing information technology training. To support this information technology training, appropriate training planning is needed for people with disabilities. In this study, training for people with disabilities was conducted. The Deaf are done per training for each training. The ranking of information technology training is analyzed using the Analytical Hierarchy Process (AHP) method and using Rapid Application Development (RAD) for the system development. This research discusses the hearing impairment, hearing, while information technology training is carried out using Microsoft Word, Microsoft Excel, Power Point, Photoshop, Initial Programming, Adobe Illustration, e-marketing, internet search, and social media. The final results show that technology training is suitable for people with disabilities.
\end{abstract}

Keywords: Analytical Hierarchy Process (AHP), Deaf, Disability, Information Technology Training

\begin{abstract}
ABSTRAK
Undang-Undang Nomor 8 Tahun 2016 menyatakan bahwa disabilitas merupakan bagian dari negara Republik Indonesia yang memiliki hak dan kewajiban yang sama. Oleh karena itu perlunya peningkatan kesejateraan sosial bagi penyandang disabilitas. Salah satu cara meningkatkannya dengan memberikan pelatihan teknologi informasi. Untuk mendukung pelatihan teknologi informasi ini diperlukan pemetaan dalam pelatihan yang sesuai untuk para penyandang disabilitas. Pada penelitian ini dilakukan pemetaan pelatihan bagi penyandang disabilitas Tuna Rungu dimana dilakukan perangkingan pada setiap pelatihan teknologi informasi berdasarkan kriteria kemampuan. Pemeringkatan pelatihan teknologi informasi di analisa menggunakan metode Analytical Hierarchy Process (AHP) dan untuk pengembangan sistem menggunakan Rapid Application Development (RAD). Pada penelitian ini membahas tentang disabilitas tuna rungu hard of hearing, dimana pelatihan teknologi informasi yang dijadikan altribut sebagai berikut microsoft word, microsoft excel, power point, photoshop, Scratch Programming, adob illustration, e-marketing, browsing internet, dan sosial media. Hasil akhir menunjukan perengkingan pelatihan teknologi yang sesuai dengan para penyandang disabilitas.
\end{abstract}

Kata Kunci: Analytical Hierarchy Process (AHP), Disabilitas, Pelatihan Teknologi Informasi, Rapid Application Development (RAD

DOI: http://dx.doi.org/10.15408/jti.v12i2.12203 


\section{PENDAHULUAN}

Word Report on Disablilty yang dirilis oleh The World Health Organization (Who, 2011) atau Organisasi Kesehatan Dunia memperkirakan sekitar $15 \%$ dari populasi dunia (7 miliar orang) hidup dengan beberapa bentuk keterbatasan fisik, dimana $2-4 \%$ di antaranya mengalami kesulitan dalam melakukan kegiatannya sehari-hari. Perkiraan jumlah penyandang disabilitas di seluruh dunia ini meningkat karena menuanya populasi dunia dan penyebaran penyakit kronis yang cukup cepat, serta peningkatan dalam metodologi yang digunakan untuk mengukur derajat ketidakmampuan fisik.

Penelitian lembaga penyelidik Ekonomi dan Masyarakat (LPEM) Fakultas Ekonomi dan Bisnis (FEB) yang dikeluarkan badan Pusat Statistik (BPS) pada tahun 2016, dijelaskan bahwa estimasi jumlah penyandang disabilitas di Indonesia sebesar 12,15\% dengan penyandang kategori sedang sebanyak 10,29\% dan kategori berat sebanyak 1,87\% [1].

Adapun data Berdasarkan hasil pendataan PT Surveyor Indonesia [2], jumlah penyadang disabilitas di 9 provinsi di indonesia sebanyak 299.203 jiwa, sekitar 67,33\% disabilitas tidak memiliki keterampilan dan perkerjaan. Dari data tersebut menjelaskan disabilitas tidak memeliki peluang dalam pekerjaan, dalam hal ini secara tidak langsung para disabilitas kehilangan haknya dalam bernegara.

Dalam konferensi indonesia ikut mengesahkan mengenai hak-hak penyandang disabilitas (Convention On The Rights of Persons With Disabilities) melalui undangundang 19 tahun 2011. Hal tersebut berdasarkan tujuan Indonesia agar para penyandang cacat/disabilitas tersebut memperoleh pemenuhan hak-haknya pemberdayaan untuk kalangan disabilitas.

Mengacu pada Undang-Undang Nomor 8 pada Tahun 2016 tentang Penyandang Disabilitas, merupakan bagian dari negara Republik Indonesia, memiliki hak dan kewajiban yang sama, Hal tersebutlah perlunya untuk peningkatan kesejateraan sosial bagi penyandang disabilitas, baik dengan memberdayakan melalui pengejaran maupun pelatihan bagi para penyandang disabilitas.

Berkaitan dengan masalah tersebut, peran teknologi di masa gobalisasi sangatlah penting oleh karena itu manusia dituntut untuk mengembangkan, serta memanfaatkan teknologi untuk dapat beradaptasi dalam keberlangsungan hidupnya. Perkembangan teknologi informasi ditandai dengan adanya pengolahan bidang pekerjaan yang awalnya dikelola dengan menggunakan cara manual dan sangat menyita waktu, maka saat ini sudah dikelola dengan hasil teknologi yang efektif dan efisien.

Oleh karena itu perlu adanya pelatihan khusus dalam bidang teknologi agar para penyadang disabilitas untuk mendorong, mengali, dan mengoptimalkan potensi dan kreatifitas disabilitas untuk dapat mengikuti pengembangan teknologi informasi. Dengan adanya pelatihan teknologi untuk disabilitas diharapkan mengubah status sosial mereka menjadi lebih baik dengan cara memandirikan kehidupan.

Pada saat ini pelatihan teknologi informasi Pustiknas (Pusat TIK Nasional kementrian komunikasi dan Informatika) untuk disabilitas sudah berjalan, namun hingga saat ini belum ada sistem yang dapat memberikan informasi dan rekomendasi pelatihan yang tepat untuk para disabilitas. oleh karena itu perlu adanya sistem pengambilan keputusan untuk mempermudah pustiknas ataupun badan latihan kerja (BLK) lainnya untuk memetakan pelatihan teknologi informasi untuk penyandang disabilitas.

\section{METODOLOGI}

Metode pengembangan sistem Rapid Application Development (RAD) dalam penelitian. Menurut Rian Ardika, Ahmad Luthfi, dan Kurniawan dalam [3], metode RAD 
terdiri dari 3 tahapan, yaitu requirement planning, design system dan implementation.

\subsection{Rencana Kebutuhan (Requirement Planning)}

Pada fase ini terdiri dari 2 tahapan, yaitu:

1. Pengumpulan data dan informasi, yaitu tahapan pengumpulan data hasil wawancara, kuesioner dan studi literatur untuk mempermudah identifikasi sistem, diantaranya:

a. Hasil wawancara dan studi literatur tentang kebutuhan user dan masalah yang di hadapi user.

b. Data mengenai sistem yang berjalan secara manual.

2. Identifikasi sistem untuk menyelesaikan masalah, yaitu:

a. Identifikasi masalah. Tahapan analisa dan identifikasi masalah yang terjadi menggunakan sistem lama.

b. Identifikasi tujuan sistem yang baru. Tahapan mengidentifikasi tujuan sistem baru untuk menyelesaikan masalah yang ada pada sistem lama.

\subsection{Proses Desain Sistem (Design System)}

Pada fase ini melakukan proses desain dan melakukan perbaikan-perbaikan apabila masih terdapat ketidaksesuaian desain antara user dan analyst.

\subsection{Implementasi (Implementation)}

Seteleh desain sistem selesai, desain sistem tersebut diimplementasikan dalam bentuk program. Fase implementation merupakan fase agar sistem dapat dioperasikan. Fase tersebut terdiri dari dua tahap, yaitu:

1. Tahap penulisan coding menggunakan HTML, CSS, JavaScript, dan PHP sebagai bahasa pemogramannya dan Phpmyadmin sebagai database.

2. Tahap pengujian sistem, untuk menjamin sistem dapat digunakan. Teknik pengujian sistem yang diterapkan adalah teknik black box functional testing.

\subsection{Alur Kerja}

Alur penelitian dapat dilihat pada Gambar 1.

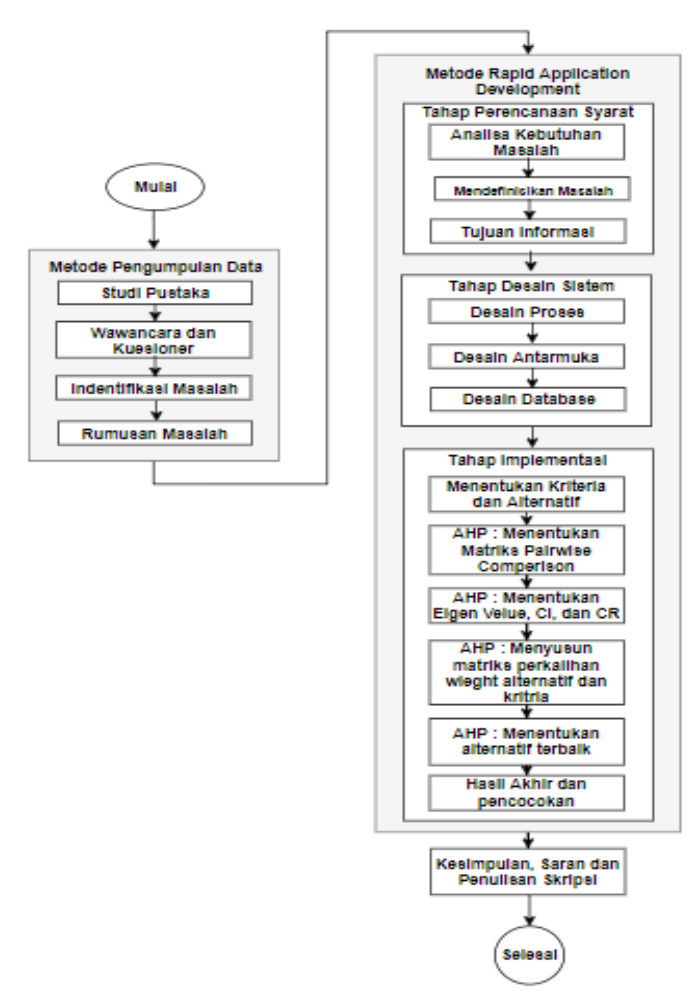

Gambar 1. Alur penelitian

\section{HASIL DAN PEMBAHASAN}

\subsection{Tahapan Pembobotan Metode AHP}

Berikut ini adalah tahapan metode analytical hierarchy process:

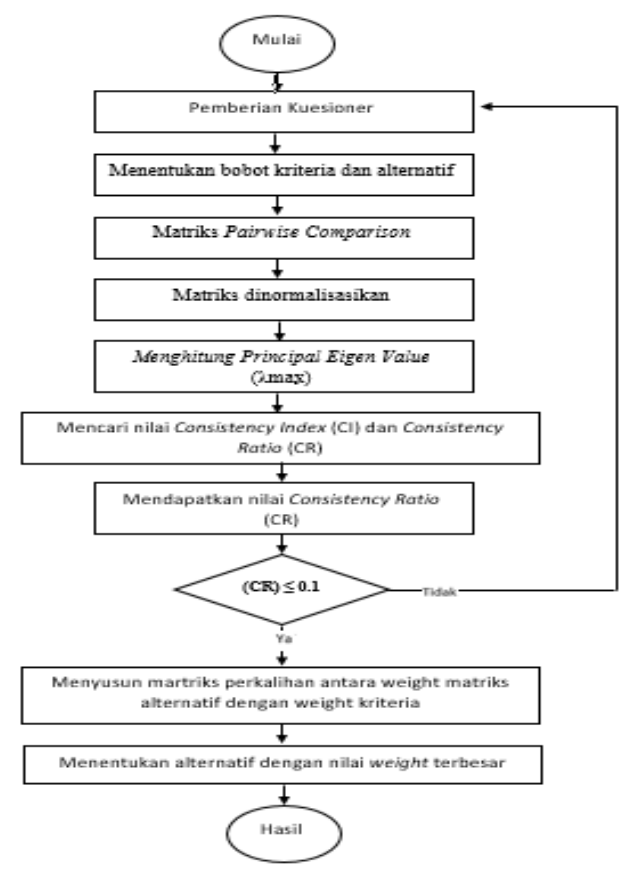

Gambar 2. Tahapan Metode AHP 


\subsection{Penilaian Kuesioner}

Dalam metode AHP yang diterapkan dalam penelitian ini kriteria penelitian dirancang sedemikian rupa agar dapat mewakili semua penilaian, Lalu kriteria tersebut dinilai bobotnya oleh decision maker. Pembobotan kriteria tersebut bertujuan untuk mencari tahu kriteria apa yang paling berpengaruh dalam penelitian ini. Nilai setiap kriteria kemudian ditentukan oleh para ahli yang menjadi narasumber penelitian melalui kuesioner. Dari hasil kuesioner tersebut, dihitung bobot kriteria dan kriteria setiap data disabilitas dan ditentukanlah pemeringkatannya. Dalam penelitian ini, digunakan skala likert dengan metode checklist untuk setiap nilai pada kuesioner untuk decision maker (Tabel 1).

Tabel 1. Penilaian kuesioner dengan skala likert

\begin{tabular}{|c|c|c|c|}
\hline No & Bobot & Keterangan & Penjelasan \\
\hline 1 & 5 & $\begin{array}{l}\text { Sangat } \\
\text { Penting }\end{array}$ & 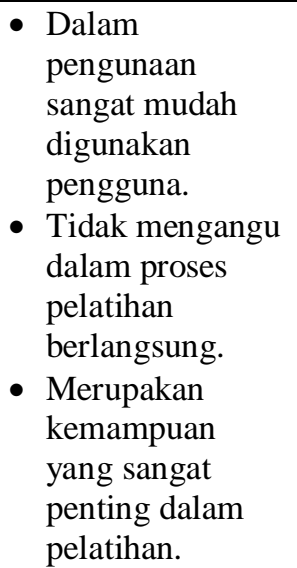 \\
\hline 2 & 4 & Penting & $\begin{array}{l}\text { Dalam } \\
\text { pengunaan } \\
\text { mudah, dan salah } \\
\text { satu kemampuan } \\
\text { yang penting } \\
\text { dalam pelatihan. }\end{array}$ \\
\hline 3 & 3 & Cukup & $\begin{array}{l}\text { - Dalam } \\
\text { pengunaan } \\
\text { cukup mudah } \\
\text { dan cukup } \\
\text { penting untuk } \\
\text { pengguna. }\end{array}$ \\
\hline 4 & 2 & $\begin{array}{l}\text { Kurang } \\
\text { Penting }\end{array}$ & $\begin{array}{l}\text { - Dalam } \\
\text { pengunaan } \\
\text { kurang penting } \\
\text { untuk penguna } \\
\text { dan sulit untuk } \\
\text { penguna. }\end{array}$ \\
\hline 5 & 1 & $\begin{array}{c}\text { Tidak } \\
\text { Penting }\end{array}$ & $\begin{array}{l}\text { - Dalam pengunan } \\
\text { sangat tidak } \\
\text { penting untuk } \\
\text { penguna dan }\end{array}$ \\
\hline
\end{tabular}

tidak penting

untuk penguna.

\subsection{Pembobotan Kriteria Untuk Tuna Rungu Hard of Hearing}

Pembobotan kriteria dilakukan oleh narasumber dari SLBN 01 Jakarta., Nilai yang diberikan oleh ketiga narasumber dicari rataratanya lalu dibuat ke dalam matriks perbandingan berpasangan sesuai skala kepentingan relatif AHP pada Tabel 2 hasilnya sebagai berikut:

Tabel 2. Data penilaian decision maker untuk kriteria

\begin{tabular}{ccccc}
\hline Kriteria & N1 & N2 & N3 & Rata-Rata \\
\hline Penglihatan & 5 & 5 & 5 & 5 \\
\hline Pendengaran & 3 & 3 & 3 & 3 \\
\hline Fisik & 4 & 4 & 4 & 4 \\
\hline
\end{tabular}

Menurut data yang diberikan, nilai rata-rata kriteria Penglihatan lebih besar dari nilai ratarata kriteria pendengaran sehingga tingkat kepentingan kriteria Penglihatan lebih unggul dibandingkan kriteria pendengaran. Oleh karena itu, matriks perbandingan berpasangan antara Penglihatan dan pendengaran diberi bobot 3 .

Nilai rata-rata kriteria Penglihatan lebih besar dari nilai rata-rata kriteria Fisik sehingga tingkat kepentingan kriteria Penglihatan lebih unggul sedikit dibandingkan kriteria Fisik. Oleh karena itu, matriks perbandingan berpasangan antara Penglihatan dan Fisik diberi bobot 2 .

Nilai rata-rata kriteria Fisik lebih besar dari nilai rata-rata kriteria Pendengaran sehingga tingkat kepentingan kriteria Fisik lebih unggul sedikit dibandingkan kriteria Pendengaran. Oleh karena itu, matriks perbandingan berpasangan antara Fisik dan pendengaran diberi bobot 2 .

\subsection{Perhitungan Bobot Kriteria Untuk Tuna Rungu Hard of Hearing}

Pada penelitian tuna rungu hard of hearing terdapat kriteria yang dianggap penting dalam penentuan pelatihan teknologi yang tebaik. Pembobotan untuk kriteria tersebut adalah sebagai berikut. Hasil pembobotan dari setiap kriteria yang diperoleh, diolah dan dimasukan ke dalam pairwise comparrison matrix seperti 
yang telihat pada Tabel 3 dan dicari konsistensi pada data.

Tahap selanjutnya normalisasi dilakukan dengan cara membagi setiap entri pada Tabel 3 dengan total masing-masing seperti pada Tabel 4.
Tabel 3. Penilaian antar kriteria tuna rungu

\begin{tabular}{cccc}
\hline Kriteria & Penglihatan & Pendengaran & Fisik \\
\hline Penglihatan & 1 & 3 & 2 \\
\hline Pendengaran & 0.3 & 1 & 0.5 \\
\hline Fisik & 0.5 & 2 & 1 \\
\hline Jumlah & 1.8 & 6 & 3.5 \\
\hline
\end{tabular}

Tabel 4. Normalisasi matrix perbandingan berpasangan kriteria tuna rungu

\begin{tabular}{ccccc}
\hline Kriteria & Penglihatan & Pendengaran & Fisik & Eigenvector $(\lambda)$ \\
\hline Penglihatan & $1 / 1.8=0.55$ & $3 / 6=0.5$ & $2 / 3.5=0.571$ & 0.539 \\
\hline Pendengaran & $0.3 / 1.8=0.182$ & $1 / 6=0.167$ & $0.5 / 3.5=0.143$ & 0.164 \\
\hline Fisik & $0.5 / 1.8=0.273$ & $2 / 6=0.333$ & $1 / 3.5=0.286$ & 0.297 \\
\hline Jumlah & 1,00 & 1,00 & 1.00 & 1.00 \\
\hline
\end{tabular}

Dari Tabel 4 diperoleh Eigenvector dari kriteria penglihatan 0.539 , dari pendengaran 0.164 , dan dari fisik 0.397 .

Langkah selanjutnya adalah dilakukan penghitungan konsistensi dengan menghitung
Weighted Sum Vector (WSM), Principal Eigen

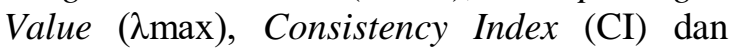
Consistency Ration (CR). Dalam menghitung Weighted Sum Vector $=($ Matrix awal $\mathrm{x}$ eigenvector) seperti pada Tabel 5.

Tabel 5. Uji konsistensi matrix kriteria

\begin{tabular}{clll}
\hline \multicolumn{2}{c}{ Weighted Sum Vector } & Perkalian Matriks & Hasil \\
\hline$\left[\begin{array}{ccc}1 & 3 & 2 \\
0.3 & 1 & 0.5 \\
0.5 & 2 & 1\end{array}\right] x\left[\begin{array}{c}0.539 \\
0.164 \\
0.297\end{array}\right]$ & $(1 * 0.52+3 * 0.16+2 * 0.28)$ & 1.62 \\
\cline { 3 - 4 } & $(0.3 * 0.52+1 * 0.16+0.5 * 0.28)$ & 0.49 \\
\hline
\end{tabular}

Menghitung principal eigen value ( $\lambda \max )$, dengan cara jumlahkan hasil weighed sum vector dibagi dengan eigenvector dengan banyaknya elemen yang ada yaitu 3, maka seperti berikut.

$$
\lambda \max =\frac{1}{3}\left(\frac{1.62}{0.539}+\frac{0.49}{0.164}+\frac{0.89}{0.29}\right)=3.013
$$

Dari $\lambda$ maks yang didapatkan, kemudian dicari Consistency Index (CI) dan Consistency Ration (CR)untuk mengetahui konsistensi data yang diperoleh.

$$
\mathrm{CI}=\frac{\lambda-\mathrm{n}}{\mathrm{n}-1}=\frac{3.013-3}{3-1}=0.00559
$$

Nilai Consistency Index (CI) yang didapat dibagi dengan Random Index (RI) yang didapatkan dari tabel Random Index (RI) sebagai berikut.

$$
\mathrm{CR}=\frac{\mathrm{CI}}{\mathrm{RI}}=\frac{0.00559}{0,58}=0.01
$$

Dari hasil penghitungan nilai Consistency Ration (CR) sebesar 0,01 dimana nilai Random Index (RI) diambil dari daftar index random konsistensi telah ditentukan nilainya dengan ukuran matrix 3, maka RI bernilai 0,58.

Oleh karena Consistency Ration $(\mathrm{CR}) \leq$ 0.1 , maka rasio konsistensi dari perhitungan diatas dinyatakan benar. Sehingga dapat disimpulkan bahwa penglihatan menjadi kriteria terpenting didalam tuna rungu sebesar $53,4 \%$ kemudian fisik $29,7 \%$ dan kemudian pendengaran $16,4 \%$.

\subsection{Pembobotan Alternatif Pada Kriteria Pendengaran Pada Tuna Rungu Hard of Hearing \\ Dalam pembobotan alternatif penulis} mendapatkan data dari membagikan kuesioner kepada decision maker, untuk alternatif pada kriteria pendengaran (Tabel 6). 
Tabel 6. Data penilaian decision maker untuk alternatif pada kriteria pendengaran

\begin{tabular}{lcccc}
\hline Pendengaran & $\begin{array}{c}\text { Decision } \\
\text { Maker } 1\end{array}$ & $\begin{array}{c}\text { Decision } \\
\text { Maker } 2\end{array}$ & $\begin{array}{c}\text { Decision } \\
\text { Maker 3 }\end{array}$ & Rata-rata \\
\hline Microsoft Word & 3 & 3 & 4 & 3,3 \\
\hline Microsoft Excel & 3 & 3 & 4 & 3,3 \\
\hline Power Point & 4 & 4 & 4 & 4 \\
\hline Scratch programming & 3 & 4 & 3 & 3,3 \\
\hline Photoshop & 5 & 3 & 5 & 4,3 \\
\hline
\end{tabular}

\subsection{Perhitungan Alternatif Pada Kriteria Pendengaran Tuna Rungu Hard of Hearing.}

Hasil pembobotan dari setiap alternatif pada kriteria pendengaran yang di peroleh, diolah dan dimasukan ke dalam pairwise comparrison matrix seperti yang telihat pada tabel 7.

Menurut data yang diberikan decision maker:

1. Nilai rata-rata microsoft word lebih rendah dari nilai e-marketing, dan browsing internet oleh karena itu matriks perbandingan berpasangan $e$-marketing dan browsing internet terhadap Microsoft Word, diberikan bobot 2. Sedangkan untuk Microsoft Word, Microsoft Excel dan sosial media memiliki nilai sama besar maka matriks perbandingan berpasangan diberikan bobot 1 .
2. Nilai rata-rata Microsoft Excel lebih rendah dari nilai e-marketing, dan browsing internet oleh karena itu matriks perbandingan berpasangan $e$-marketing dan browsing Internet terhadap microsoft excel, diberikan bobot 2. Sedangkan untuk Microsoft Excel dan sosial media memiliki nilai sama besar maka matriks perbandingan berpasangan diberikan bobot 1.

3. Nilai rata-rata Sosial Media lebih rendah dari nilai e-marketing, dan browsing internet. Oleh karena itu, matriks perbandingan berpasangan $e$-marketing dan browsing Internet terhadap sosial media, diberikan bobot 2 .

4. Nilai rata-rata e-marketing sama dengan nilai dari browsing internet maka matriks berpasangan diberikan bobot 1 .

Tabel 7. Matriks perbandingan berpasangan untuk alternatif pendengaran pada tuna rungu

\begin{tabular}{lccccc}
\hline Pendengaran & $\begin{array}{c}\text { Microsoft } \\
\text { Word }\end{array}$ & $\begin{array}{c}\text { Microsoft } \\
\text { Excel }\end{array}$ & $\begin{array}{c}\text { Power } \\
\text { Point }\end{array}$ & $\begin{array}{c}\text { Scratch } \\
\text { Programming }\end{array}$ & Photoshop \\
\hline Microsoft Word & 1 & 1 & 0.5 & 1 & 0.3 \\
\hline Microsoft Excel & 1 & 1 & 0.5 & 1 & 0.3 \\
\hline Power Point & 2 & 2 & 1 & 2 & 0.5 \\
\hline Scratch Programming & 1 & 1 & 0.5 & 1 & 0.3 \\
\hline Photoshop & 3 & 3 & 2 & 3 & 1 \\
\hline Jumlah & 8 & 8 & 4.5 & 8 & 2.5 \\
\hline
\end{tabular}

Setelah didapatkan matriks perbandingan berpasangan pada Tabel 6 langkah selanjutnya adalah normalisasi matriks. Dari hasil matriks normalisasi, didapatkan eigen vektor yang menjadi prioritas dalam alternatif terbaik dari alternatif pendengaran yaitu microsoft word mendapatkan bobot 0.124 , microsoft excel 0.124 , power point 0.234 , scretch programing 0.124, dan photoshop 0.394 (Tabel 7). 
Tabel 8. Matriks normalisasi dari matriks berpasangan untuk alternatif pendengaran pada tuna rungu

\begin{tabular}{|c|c|c|c|c|c|c|}
\hline Perbandingan & $\begin{array}{l}\text { Microsoft } \\
\text { Word }\end{array}$ & $\begin{array}{l}\text { Microsoft } \\
\text { Excel }\end{array}$ & $\begin{array}{l}\text { Power } \\
\text { Point }\end{array}$ & $\begin{array}{c}\text { Scratch } \\
\text { Programming }\end{array}$ & Photoshop & Eigenvector \\
\hline $\begin{array}{l}\text { Microsoft } \\
\text { Word }\end{array}$ & $1 / 8=0.125$ & $1 / 8=0.125$ & $\begin{array}{c}0.5 / 4,5= \\
0.111\end{array}$ & $1 / 8=0.125$ & $\begin{array}{c}0.3 / 2.5= \\
0.133\end{array}$ & 0.124 \\
\hline $\begin{array}{l}\text { Microsoft } \\
\text { Excel }\end{array}$ & $1 / 8=0.125$ & $1 / 8=0.125$ & $\begin{array}{c}0.5 / 4,5= \\
0.111\end{array}$ & $1 / 8=0.125$ & $\begin{array}{c}0.3 / 2.5= \\
0.133\end{array}$ & 0.124 \\
\hline Power Point & $2 / 8=0.250$ & $2 / 8=0.250$ & $\begin{array}{l}1 / 4.5= \\
0.222\end{array}$ & $2 / 8=0.250$ & $\begin{array}{c}0.5 / 2.5= \\
0.200\end{array}$ & 0.234 \\
\hline $\begin{array}{l}\text { Scratch } \\
\text { Programming }\end{array}$ & $1 / 8=0.125$ & $1 / 8=0.125$ & $\begin{array}{c}0.5 / 4.5= \\
0.111\end{array}$ & $1 / 8=0.125$ & $\begin{array}{c}0.3 / 2,5= \\
0.133\end{array}$ & 0.124 \\
\hline Photoshop & $3 / 8=0.375$ & $3 / 8=0.375$ & $\begin{array}{c}2 / 4.5= \\
0.444\end{array}$ & $3 / 8=0.375$ & $\begin{array}{l}1 / 2.5= \\
0.400\end{array}$ & 0.394 \\
\hline Jumlah & 1 & 1 & 1 & 1 & 1 & 1 \\
\hline
\end{tabular}

Langkah selanjutnya adalah dilakukan penghitungan konsistensi dengan menghitung Weighted Sum Vector (WSM), Principal Eigen Value ( $\lambda \max )$, Consistency Index (CI) dan
Consistency Ration (CR). Dalam menghitung Weighted Sum Vector $=($ Matrix awal $\mathrm{x}$ eigenvector) seperti pada Tabel 9.

Tabel 9. Uji konsistensi matrix alternatif pada kriteria pendengaran

\begin{tabular}{|c|c|c|c|c|c|}
\hline \multicolumn{4}{|c|}{ Weighted Sum Vector } & Perkalian Matriks & Hasil \\
\hline$\Gamma 1$ & 10.5 & $\begin{array}{ll}1 & 0.31]\end{array}$ & {$[0.124]$} & $(1 * 0.124+1 * 0.124+0,5 * 0.234+1 * 0.124+0.3 * 0.394)$ & 0.607 \\
\hline 1 & $1 \quad 0.5$ & $1 \quad 0.31$ & 0.124 & $(1 * 0.124+1 * 0.124+0,5 * 0.234+1 * 0.124+0.3 * 0.394)$ & 0.607 \\
\hline 2 & 2 & 0.5 P & $\mathrm{x} 0.234$ & $(2 * 0.124+2 * 0.124+1 * 0.234+2 * 0.124+0.5 * 0.394)$ & 1.175 \\
\hline 1 & $1 \quad 0.5$ & 0.3 & 0.124 & $(1 * 0.124+1 * 0.124+0,5 * 0.234+1 * 0.124+0.3 * 0.394)$ & 0.607 \\
\hline $\mathrm{L}_{3}$ & 2 & 3 & L 0.394 & $(3 * 0.124+3 * 0.124+2 * 0.234+3 * 0.124+1 * 0.394))$ & 1.978 \\
\hline
\end{tabular}

Menghitung principal eigen value $(\lambda \max )$, dengan cara, jumlahkan hasil weighed sum vector dibagi dengan eigenvector dengan banyaknya elemen yang ada yaitu 3, maka seperti berikut.

$\lambda$ maks $=\frac{1}{5}\left(\frac{0.607}{0.124}+\frac{0.607}{0.124}+\frac{1.175}{0.234}+\frac{0.607}{0.124}+\right.$ $\left.\frac{1.978}{0.394}\right)=5.0208$

Dari $\lambda$ maks yang didapatkan, kemudian dicari Consistency Index (CI) dan Consistency Ration (CR) untuk mengetahui konsistensi data yang diperoleh.

$$
\mathrm{CI}=\frac{\lambda-\mathrm{n}}{n-1}=\frac{5.0208-5}{5-1}=-0.0052
$$

Nilai Consistency Index (CI) yang didapat dibagi dengan Random Index (RI) yang didapatkan dari tabel Random Index (RI) sebagai berikut.

$$
\mathrm{CR}=\frac{\mathrm{CI}}{R I}=\frac{0.0052}{1.12}=-0,00464
$$

Dari hasil perhitungan diperoleh nilai Consistency Ration (CR) sebesar - 0,00464 dimana nilai Random Index (RI) diambil dari daftar Index Random Konsistensi yang telah ditentukan nilainya dengan ukuran matriks 5, maka RI bernilai 1,12. 
Oleh karena itu Consistency Ration $(\mathrm{CR}) \leq$ 0.1 maka rasio konsistensi dari perhitungan diatas dinyatakan benar. Sehingga dapat disimpulkan alternatif pada kriteria pendengaran tuna rungu dengan bobot $12,4 \%$ untuk microsoft word, $12,4 \%$ untuk microsoft excel, 23,4\% untuk power point, $12,4 \%$ untuk Scretch Programing, dan 39,4\% untuk Photoshop.

Tabel 10. Matriks normalisasi dari matriks berpasangan untuk alternatif pendengaran pada tuna rungu

\begin{tabular}{|c|c|c|c|c|c|c|}
\hline Fisik & $\begin{array}{l}\text { Microsoft } \\
\text { Word }\end{array}$ & $\begin{array}{c}\text { Microsoft } \\
\text { Excel }\end{array}$ & $\begin{array}{c}\text { Power } \\
\text { Point } \\
\end{array}$ & $\begin{array}{c}\text { Scratch } \\
\text { Programing } \\
\end{array}$ & Photoshop & Eigenvektor \\
\hline $\begin{array}{l}\text { Microsoft } \\
\text { Word }\end{array}$ & $\begin{array}{l}1 / 6.5= \\
0.154\end{array}$ & $\begin{array}{c}0.5 / 3.3= \\
0.150\end{array}$ & $\begin{array}{l}2 / 11= \\
0.182\end{array}$ & $1 / 6.5=0.154$ & $\begin{array}{c}0.5 / 3.3= \\
0.153\end{array}$ & 0.158 \\
\hline $\begin{array}{l}\text { Microsoft } \\
\text { Excel }\end{array}$ & $\begin{array}{c}2 / 6.5= \\
0.300\end{array}$ & $\begin{array}{l}1 / 3.3= \\
0.300\end{array}$ & $\begin{array}{l}3 / 11= \\
0.273\end{array}$ & $2 / 6.5=0.300$ & $\begin{array}{c}1 / 3.3= \\
0.300\end{array}$ & 0.298 \\
\hline Power Point & $\begin{array}{c}0.5 / 6.5= \\
0.077\end{array}$ & $\begin{array}{c}0.5 / 3.3= \\
0.100\end{array}$ & $\begin{array}{l}1 / 11= \\
0.091\end{array}$ & $\begin{array}{c}0.5 / 6.5= \\
0.077\end{array}$ & $\begin{array}{c}0.3 / 2.3= \\
0.100\end{array}$ & 0.089 \\
\hline $\begin{array}{l}\text { Scretch } \\
\text { Programing }\end{array}$ & $\begin{array}{l}1 / 6.5= \\
0.154\end{array}$ & $\begin{array}{c}1 / 3.3= \\
0.150\end{array}$ & $\begin{array}{l}2 / 11= \\
0.182\end{array}$ & $1 / 6.5=0.154$ & $\begin{array}{c}0.5 / 3.3= \\
0.150\end{array}$ & 0.158 \\
\hline Photoshop & $\begin{array}{l}2 / 6.5= \\
0.300\end{array}$ & $\begin{array}{c}0.3 / 3.3= \\
0.300\end{array}$ & $\begin{array}{l}3 / 11= \\
0.273\end{array}$ & $2 / 6.5=0.300$ & $\begin{array}{c}1 / 3.3= \\
0.300\end{array}$ & 0.298 \\
\hline Jumlah & 1.000 & 1.000 & 1.000 & 1.000 & 1.000 & 1.000 \\
\hline
\end{tabular}

Dari hasil matriks normalisasi (Tabel 10), didapatkan eigen vektor yang menjadi prioritas dalam alternatif terbaik dari alternatif pendengaran yaitu Microsoft Word mendapatkan bobot 0.158, Microsoft Excel 0.298, Power Point 0.089, Scretch Programing 0.158, dan Photoshop 0.298.
Langkah selanjutnya adalah dilakukan penghitungan konsistensi dengan menghitung Weighted Sum Vector (WSM), Principal Eigen

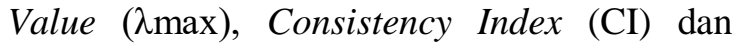
Consistency Ration (CR). Dalam menghitung Weighted Sum Vector $=($ Matrix awal $\mathrm{x}$ eigenvector) seperti pada Tabel 11.

Tabel 11. Uji konsistensi matrix alternatif pada kriteria 3

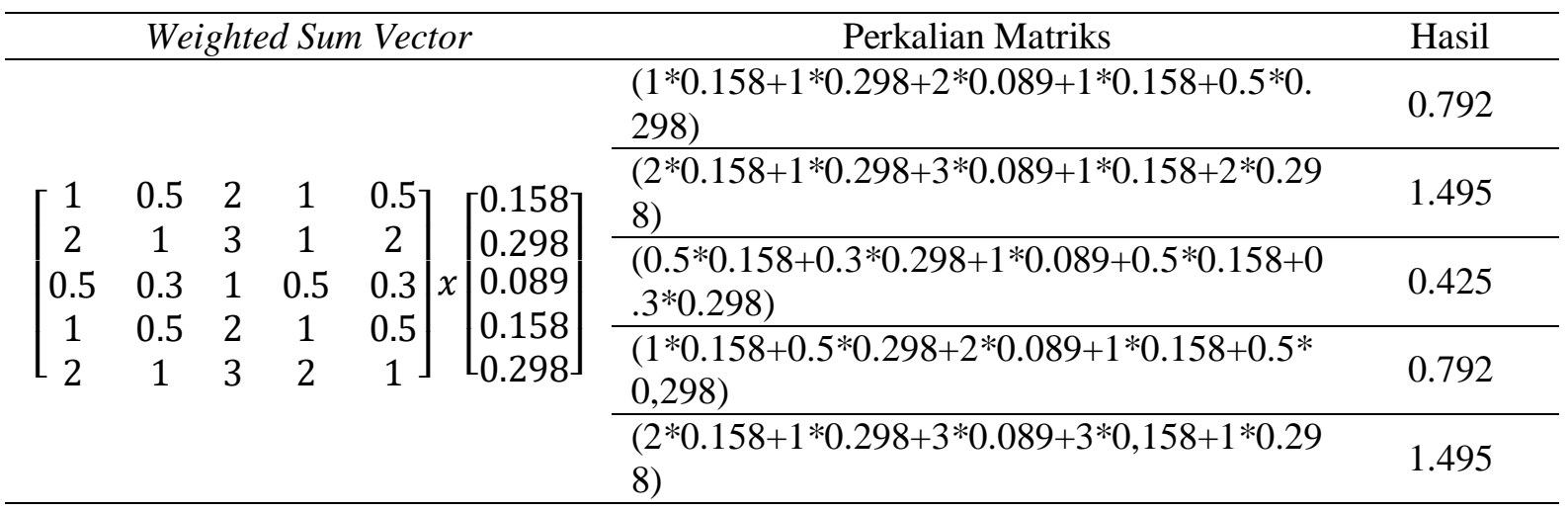

Menghitung principal eigen value ( $\lambda \max )$, dengan cara, jumlahkan hasil weighed sum vector dibagi dengan eigenvector dengan banyaknya elemen yang ada yaitu 3, maka seperti berikut:

$$
\begin{gathered}
\lambda \text { maks }=\frac{1}{5}\left(\frac{0.792}{0.158}+\frac{1.495}{0.298}+\frac{0.425}{0.089}+\frac{0.792}{0.148}+\right. \\
\left.\frac{1.495}{0.298}\right)=5.036
\end{gathered}
$$

Dari $\lambda$ maks yang didapatkan, kemudian dicari Consistency Index (CI) dan Consistency Ration (CR) untuk mengetahui konsistensi data yang diperoleh.

$$
\mathrm{CI}=\frac{\lambda-\mathrm{n}}{n-1}=\frac{5.036-5}{5-1}=-0.009
$$

Nilai Consistency Index (CI) yang didapat dibagi dengan Random Index (RI) yang 
didapatkan dari tabel Random Index (RI) sebaga berikut.

$$
\mathrm{CR}=\frac{\mathrm{CI}}{R I}=\frac{0.009}{1.12}=-0,008
$$

Dari hasil perhitungan diperoleh nilai Consistency Ration (CR) sebesar - 0,008 dimana nilai Random Index (RI) diambil dari daftar Index Random Konsistensi yang telah ditentukan nilainya dengan ukuran matriks 5 , maka RI bernilai 1.12 .

Oleh karena Consistency Ration $(\mathrm{CR}) \leq$ 0.1 maka rasio konsistensi dari perhitungan di atas dinyatakan benar.
Sehingga dapat disimpulkan alternatif pada penglihatan dengan bobot $15,8 \%$ untuk Microsoft Word, 29,8\% untuk Microsoft Excel, 8.9\% untuk Power Point, 15,8\% untuk Scretch Programing, dan 29,8\% untuk Photoshop.

\subsection{Penghitungan Hasil Akhir Kriteria dan Alternatif Tuna Rungu}

Perhitungan hasil akhir dari setiap kriteria dan alternatif yang diperoleh, selanjutnya dikalikan dengan perkalian matriks seperti yang ditunjukan pada Tabel 12.

Tabel 12. Nilai akhir kriteria dan alternatif untuk tuna rungu

\begin{tabular}{ccccccc}
\hline \multirow{2}{*}{ Kriteria } & \multirow{2}{*}{ Bobot } & \multicolumn{5}{c}{ Alternatif } \\
\cline { 3 - 7 } & & $\begin{array}{c}\text { Microsoft } \\
\text { Word }\end{array}$ & $\begin{array}{c}\text { Microsoft } \\
\text { Excel }\end{array}$ & $\begin{array}{c}\text { Power } \\
\text { Point }\end{array}$ & $\begin{array}{c}\text { Scretch } \\
\text { Programing }\end{array}$ & Photoshop \\
\hline Penglihatan & 0.538 & 0.297 & 0.157 & 0.089 & 0.157 & 0.297 \\
\hline Pendengaran & 0.163 & 0.157 & 0.123 & 0.234 & 0.123 & 0.394 \\
\hline Fisik & 0.297 & 0.157 & 0.297 & 0.089 & 0.157 & 0.297 \\
\hline
\end{tabular}

Langkah selanjutnya untuk menentukan bobot tertinggi untuk pelatihan teknologi disabilitas tuna rungu hard of hearing, dengan perkalihan matriks seperti berikut pada Tabel 13.

Tabel 13. Hasil perangkingan pelatihan teknologi untuk tuna rungu

\begin{tabular}{ccccc}
\hline \multirow{2}{*}{ Alternatif } & \multicolumn{3}{c}{ Kriteria } & \multirow{2}{*}{ Hasil } \\
\cline { 2 - 4 } & Penglihatan & Pendengaran & Fisik & \\
\hline Microsoft Word & 0.16040 & 0.02028 & 0.04693 & 0.22762 \\
\hline Microsoft Excel & 0.08509 & 0.02028 & 0.08846 & 0.19385 \\
\hline Power Point & 0.04792 & 0.03839 & 0.02643 & 0.11275 \\
\hline $\begin{array}{c}\text { Scratch } \\
\text { Programming }\end{array}$ & 0.16043 & 0.02028 & 0.04693 & 0.15231 \\
\hline Photoshop & 0.08509 & 0.06453 & 0.08848 & 0.31345 \\
\hline
\end{tabular}

Dapat dilihat dari Tabel 12 dan Tabel. 13 bobot dari setiap kriteria yang didapatkan dikalikan dengan hasil setiap alternatif pada penelitian tuna darsa pada amputasi tangan pada Tabel 13 dapat dilihat jumlah dengan peringkat tertinggi sebesar $31,3 \%$ yaitu Photoshop, lalu pada peringkat kedua dengan nilai $22,7 \%$ yaitu Microsoft Word, kemudian pada peringkat ketiga dengan nilai 19,3\% yaitu Microsoft Excel, diperingkat keempat dengan nilai 15,2\% Scratch Programing, dan yang terakhir pada pringkat kelima yaitu dengan nilai $11,2 \%$ yaitu Power Point.

\subsection{Use Case Diagram}

\subsubsection{Use Case Diagram Admin}

Admin adalah orang yang memiliki kewenangan untuk dapat menghapus, mengedit, dan menambah user untuk menggunakan aplikasi. 


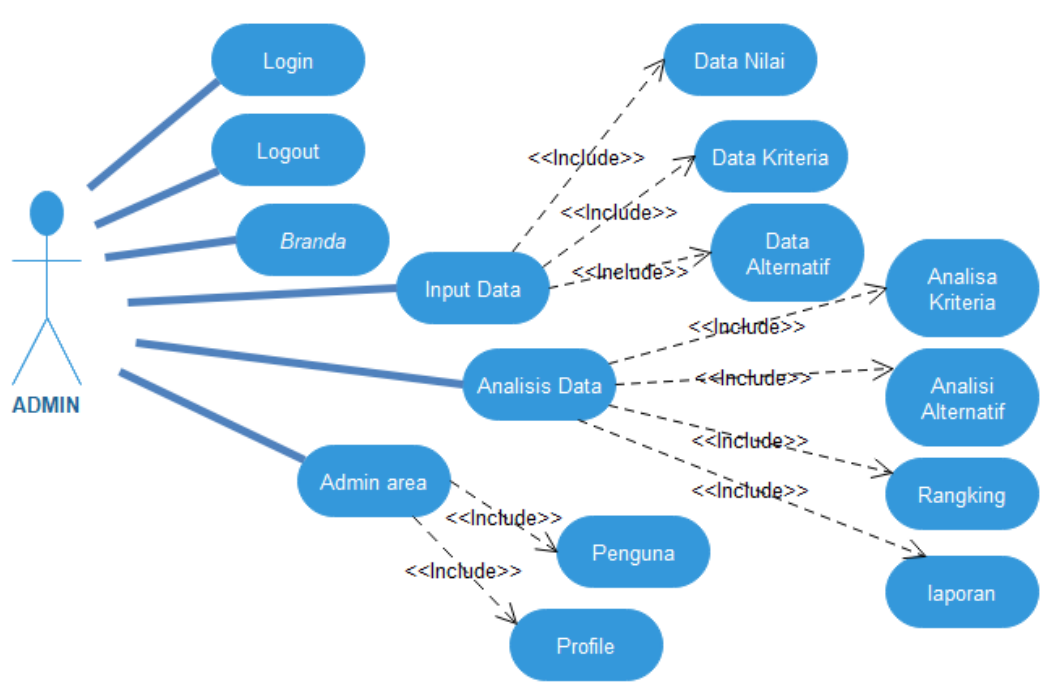

Gambar 3. Use Case Diagram Admin

\subsubsection{Use Case Diagram User}

User adalah pengguna aplikasi yang ingin mengetahui pelatihan teknologi informasi untuk penyandang disabilitas dan memiliki perangkat baik melalui PC. User dapat mengakses semua fitur menggunakan perangkat baik yang terpasang internet maupun tidak.

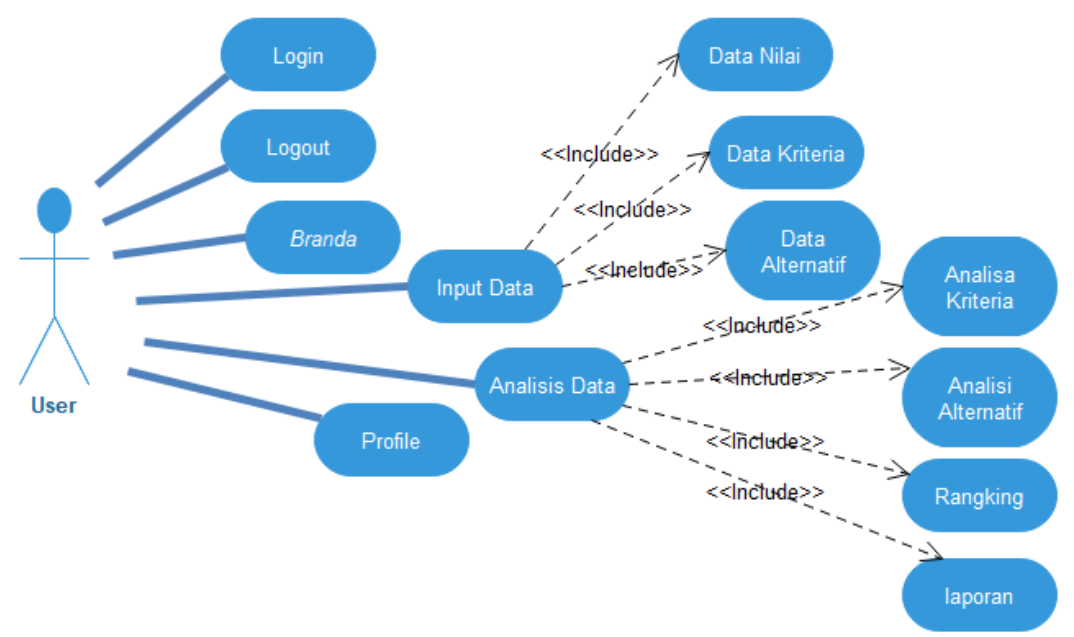

Gambar 4. Use case diagram user

\section{HASIL DAN PEMBAHASAN}

Penelitian tuna rungu hard of hearing data diambil dari SLBN (Sekolah Luar Biasa
Negeri) 1 Lebak Bulus pada tangal 20 April 2018. Data diperoleh dengan wawancara dan memberikan kuesioner decision maker lalu di olah menggunakan metode AHP dan mendapatkan hasil seperti pada Gambar 5. 


\begin{tabular}{|l|l|l|l|l|}
\hline \multirow{2}{*}{ Alternatif } & \multicolumn{3}{|c}{ Kriteria } & \multirow{2}{*}{ Hasil } \\
\cline { 2 - 4 } & penglihatan & pendengaran & fisik & \\
\hline Microsoft Word & 0.1604020765136 & 0.020283373706108 & 0.046935650458225 & 0.227621100677933 \\
\hline Microsoft Excel & 0.085099346825957 & 0.020283373706108 & 0.088468079683536 & 0.193850800215601 \\
\hline Power Point & 0.04792877301125 & 0.038390869846184 & 0.026434611085187 & 0.11275425394262101 \\
\hline Scratch Programming & 0.085099346825957 & 0.020283373706108 & 0.046935650458225 & 0.15231837099029 \\
\hline Photoshop & 0.16043149578428 & 0.064539672816153 & 0.088484305573124 & 0.313455474173557 \\
\hline Jumlah & 1.00000 & 1.00000 & 1.00000 & 1.00000 \\
\hline
\end{tabular}

Gambar 5. Hasil perangkingan tuna rungu

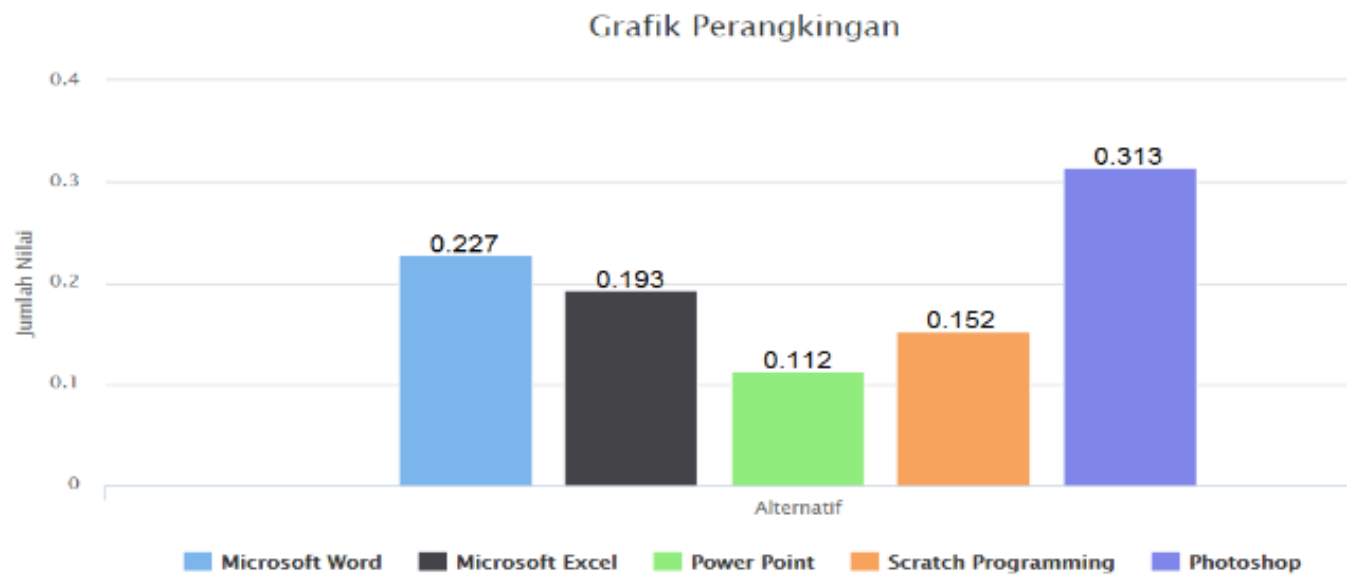

Gambar 6. Grafik perangkingan tuna rungu

\section{KESIMPULAN}

Dari hasil di atas dapat kita lihat perangkingan untuk pelatihan teknologi informasi untuk tuna rungu hard of hearing, Photoshop lebih unggul dibandingkan pelatihan teknologi yang lain dengan nilai 0.313 . Sedangkan Microsoft Word menempati peringkat kedua dengan nilai 0.227 , di posisi ketiga dan keempat ada Microsoft Excel dan Scretch Programing dengan nilai 0.193 dan 0.152. dan untuk peringkat terakhir Power Point dengan nilai 0.112 . Hasil tersebut sesuai dengan perhitungan manual yang dilakukan, dimana Photoshop merupakan pelatihan yang paling tinggi nilainya sesuai dengan bobot yang diberikan oleh decision maker tuna rungu. hard of hearing.
Pada pengembangan aplikasi sistem pengambilan keputusan pemetaan pelatihan teknologi informasi ini dibangun menggunakan metode Analytic Hierarchy Process (AHP) sebagai metode pembobotan krteria dan pemilihan alternatif. Pemilihan alternatif pada sistem ini adalah pelatihan teknologi informasi yang direkomendasikan oleh sistem berdasarkan penghitungan kriteria dan penghitungan setiap setiap alternative.

Hasil pengujian menunjukan bahwa tuna runggu hard of hearing pada pelatihan Photoshop dengan nilai 0.313 lebih unggul dari pada pelatihan Microsoft Word, Microsoft Excel, Scretch Programing, dan Power Point.

\section{DAFTAR PUSTAKA}

[1] A., K. S. Educating Exceptional Children (Second Edition). Boston: Houghton Mifflin Company, 1992.

[2] Amrizal, V dan Aini, Q. Kecerdasan 
Buatan. Jakarta: Halaman Moeka Publishing, 2013.

[3] Arifa, S. Sistem Pendukung Keputusan Pemilihan Asupan Kalori Pada Penderita Diabetes Melitus Berbasis Progressive Web App (PWA) dengan Metode Simple Additive Weighting (SAW). UIN syarif Hidayatullah Jakarta, 2017.

[4] Aris, Mohammad. Perancangan Sistem Pendukung Keputusan Seleksi Kelayakan Penerimaan Bantuan Beras Miskin (Raskin) untuk Masyarakan Misikin Dengan Metode TOPSIS (The Technique for Order Preferences by Similarity to Ideal Solution). UIN Jakarta, 2014.

[5] Aswati, S. Model Rapid Application Development Dalam Rancang Bangun Sistem Informasi Pemasaran Rumah (Studi Kasus : Perum Perumnas Cabang Medan), 2016.

[6] Daniel P. Hallahan, James M. Kauffman, dan P. C. P. Pullen'sExceptional Learners: An Introduction to Special Education, 2011.

[7] Dennis, A. System Analysis \& Design. America: Wiley.inc, 2012.

[8] Efendi, M. Pengantar Psikopedagogik Anak Berkelainan. Bumi Aksara, 2008.

[9] Gayatri, Vyas dan Misal Chetan S. Comparative Study of Different MultiCriteria Decision-making Methods. India: College of Engineering Pune, 2013.

[10] Haviluddin. Memahami Penggunaan UML (Unified Modelling Language), 2011.

[11] Hidayatullah, P. Pemrograman Web. Informatika Bandung, 2014.

[12] Kadir, A. Pengenalan Sistem Informasi. Yogyakarta: Andi, 2014.

[13] Kendall, K. System Analysis and Design 8th Edition. New Jersey: Prentice Hall, 2011.

[14] Kendall, K. E., \& Kendall, J. E. Analisis dan Perancangan Sistem (5 ed.). (T. A. Hafedh, Trans.) Jakarta: PT Indeks, 2010.

[15] Kusrini. Konsep dan Aplikasi Sistem Pengambilan Keputusan. Yogyakarta: ANDI, 2007.

[16] Lathifatun, Nisa. Perancangan Sistem Pendukung Keputusan Pemilihan Menu Makanan Sehat Bagi Penderita Obesitas Berbasis Android Dengan Metode Analitical Hierarchy Proces (AHP). UIN Jakarta, 2016.

[17] Mediaadisabilitas. Penyandang disabilitas adalah dari google, 2016. Retrieved from http://mediadisabilitas.org/uraian/ind/pe ngertian

[18] Pressman, R. S. Software Engineering: A Practitioner's Approach. Jakarta: McGraw-Hill International Edition, 2009.

[19] Poppy, Rachmayanti. Analisis Pemilihan Karyawan Terbaik Di Bali IPTEKnet BPPT Menggunakan Metode Analytic Hieranrchy Process. UIN Jakarta, 2013.

[20] Raharjo, B. Modul Pemrograman web (HTML, PHP, \& MySQL). Bandung: Modula, 2014.

[21] Reefani, N. K. Panduan Anak Berkebutuhan Khusus. Yogyakarta: Imperium, 2013.

[22] Riyanto. Membuat Sendiri Aplikasi Ecommerce dengan PHP dan MySQL Menggunakan. Yogyakarta: Andi, 2011.

[23] Rizky, S. Konsep Dasar Rekayasa Perangkat Lunak (PT. Presta). Jakarta, 2011.

[24] Rosa. Rekayasa Perangkat Lunak Terstruktur Dan Berorientasi Objek. Bandung: INFORMATIKA, 2015.

[25] Satzinger, J. W., Jackson, R. B., \& Burd, S. D. System Analysis and Design with the Unified Process (1 ed.). Boston: Cengage Learning, 2010. 